\title{
Evaluation of Quality of Concrete Road Project based on Statistical Quality Control Techniques
}

\author{
Ajay V. Chopane ${ }^{1}$ and Dr. Abhay S. Wayal ${ }^{2}$ \\ ${ }^{1}$ Civil \& Environmental Engineering Department, Veermata Jijabai Technological Institute, Mumbai 400019, \\ India. \\ ${ }^{2}$ Associate Professor, Civil \& Environmental Engineering Department, Veermata Jijabai Technological \\ Institute, Mumbai 400019, India
}

\begin{abstract}
The statistical quality control techniques have been proved as the efficient techniques for the evaluation of quality of any products or services. These techniques such as statistical process control, acceptance sampling plans are used for evaluation of quality of concrete road in Mumbai region in this paper. The statistical process techniques as control charts which are helpful for detecting causes of variation in the process of manufacture, are used in order to evaluate quality of concrete road during construction. The acceptance sampling plan as variable acceptance sampling plan is used for evaluation of quality of concrete road after the construction and also a control chart is developed to show variation in the density of road.

Keywords: Quality control, Statistical process control, Acceptance sampling, Concrete road, Quality Assurance.
\end{abstract}

\section{Introduction}

Quality may be defined in many ways as Quality means those features of products which meet customer needs and there by provide customer satisfaction (Juran, 1920), in another way quality means freedom from deficiencies. It is necessary to control quality which directly affects on customers satisfaction and it will have to affect on the cost of project.

Quality control means the process through which we measure the performance of product or service and compare it with specification and if any deviation found then it acts on that deviation. If statistics is involved in in quality control, then quality of any products or services will be improved and it will be easy to detect the factors behind the deviation of process.

Statistical quality control techniques are extremely useful in quality control. These techniques help to monitor the quality of product and also help to evaluate performance of product or service. These techniques can be divided in two categories as statistical process control, acceptance sampling plan. The statistical process control generally deals with the selection of sample from the process and deciding whether the process is producing as per the specified range. Statistical process control tools such as control charts( $\mathrm{x}$ and $\mathrm{r}$ ) are used to monitor the production process. A control chart is a graph that shows whether a sample of data falls within common or normal range of variation. The control limits of control charts separate common from assignable causes of variation. Another technique of statistical quality control that is acceptance sampling plan is generally used to compute the quality of product which is produced. There are two types of acceptance sampling plan such as variable and attribute sampling plan. These plans can be used to evaluate the quality of accomplished product.

This paper focused on the concept of statistical quality control techniques to evaluate the quality of concrete road project. In this paper, the evaluation of quality of concrete road is divided in two section. In first section the quality of concrete road during construction is evaluated by using statistical process control tools such as control charts and in second section the quality of concrete road is evaluated by using acceptance sampling plan after the construction.

\section{Evaluation Of Quality During The Construction Of Concrete Road}

In this evaluation, statistical process control tool i.e. control chart $(\overline{\mathrm{X}})$ is drawn in order to check process consistency which produces concrete. Generally, quality during construction of concrete road is based on cube compressive strength. In this concrete road project, three cubes are tested for every 150 cum of concrete work. As the whole concrete road is of M40 grade so a trial of 25 samples of cube are taken in order to calculate the control limits for $\overline{\mathrm{X}}$ chart. Also a range chart is drawn in order to show variation in the observation of reading of compressive strength of cube.

The observations and calculations of cube compressive strength are shown below. Based on this for first trial, control limits for control chart $(\overline{\mathrm{X}})$ are calculated by using following equations. In order to calculate control limit, $95 \%$ probability is assumed. The factors as $\mathrm{D}_{3}, \mathrm{D}_{4}$ and $\mathrm{A}_{2}$ are calculated based on the probability and observation in the sample 
Table 1. Observation table for cube compressive strength

\begin{tabular}{|c|c|c|c|c|c|c|}
\hline \multirow[b]{2}{*}{ Sr.No } & \multirow[t]{2}{*}{ Chainage } & \multicolumn{3}{|c|}{ Compressive Strength of Core $\left(\mathrm{N} / \mathrm{mm}^{2}\right)$} & \multirow[t]{2}{*}{ Average } & \multirow[t]{2}{*}{ Range } \\
\hline & & 1 & 2 & 3 & & \\
\hline 1 & 1510 to 1570 RHS & 45.60 & 45.78 & 44.98 & 45.45 & 0.8 \\
\hline 2 & 1510 to 1555 RHS & 45.33 & 45.78 & 45.71 & 45.41 & 0.45 \\
\hline 3 & 1570 to 1600 RHS & 44.89 & 45.56 & 45.78 & 45.41 & 0.89 \\
\hline 4 & 1555 to 1575 RHS & 44.44 & 45.78 & 45.33 & 45.18 & 1.34 \\
\hline 5 & 1625 to 1656 and 1659 to 1680 RHS & 45.56 & 45.78 & 46.22 & 45.85 & 0.66 \\
\hline 6 & 1600 to 1640 RHS & 44.89 & 50.22 & 54.44 & 49.85 & 9.55 \\
\hline 7 & 1750 to 1774 RHS & 51.33 & 53.33 & 53.33 & 52.66 & 2 \\
\hline 8 & 1752 to 1770 & 51.44 & 55.07 & 44.93 & 50.55 & 10.14 \\
\hline 9 & 1640 to 1685 and 1800 to 1825 RHS & 50.22 & 49.33 & 50 & 49.85 & 0.89 \\
\hline 10 & 1785 to 1830 RHS & 50.22 & 49.78 & 50.89 & 50.3 & 1.11 \\
\hline 11 & 1770 to 1785 and 1860 to 1910 RHS & 47.11 & 48 & 49.33 & 48.15 & 2.22 \\
\hline 12 & 1830 to 1860 RHS & 48 & 50.22 & 49.56 & 49.26 & 2.22 \\
\hline 13 & 1865 to 1910 and 1785 to 1830 RHS & 48.89 & 46.67 & 48.44 & 48 & 2.22 \\
\hline 14 & 1830 to 1860 and 1750 to 1785 RHS & 46.67 & 45.33 & 48.44 & 46.81 & 3.11 \\
\hline 15 & 1730 to 1745 and 1830 to 1870 & 46.67 & 44.22 & 44.44 & 45.11 & 2.45 \\
\hline 16 & 1865 to 1910 RHS & 49.33 & 48.44 & 46.67 & 48.15 & 2.66 \\
\hline 17 & 1715 to 1730 RHS & 45.33 & 49.33 & 48 & 47.55 & 4 \\
\hline 18 & 1711 to 1750 & 46.67 & 48.89 & 48.44 & 48 & 2.22 \\
\hline 19 & 1350 to 1395 RHS & 50.22 & 49.78 & 48.44 & 49.48 & 1.78 \\
\hline 20 & 1330 to 1360 RHS & 48.89 & 50.22 & 46.67 & 48.59 & 3.55 \\
\hline 21 & 1350 to 1395 RHS & 47.11 & 48.44 & 48 & 47.85 & 1.33 \\
\hline 22 & 2740 to 2785 RHS & 48.44 & 49.33 & 48.67 & 48.81 & 0.89 \\
\hline 23 & 1310 to 1350 & 50.22 & 48.89 & 48 & 49.04 & 2.22 \\
\hline 24 & 2685 to 2745 RHS & 48.44 & 49.78 & 49.33 & 49.18 & 1.34 \\
\hline 25 & 2670 to $2720 \mathrm{RHs}$ & 48.44 & 49.78 & 49.13 & 49.18 & 1.34 \\
\hline
\end{tabular}

Control limit calculation

Control limits for $\overline{\mathrm{X}}$ Chart

Centre line $=\overline{\overline{\mathrm{x}}}=\left(\overline{\mathrm{x}}_{1}+\overline{\mathrm{x}}_{2}+\ldots+\overline{\mathrm{x}}_{\mathrm{n}}\right) / \mathrm{n}$

$=48.1468$

U.C.L $=\overline{\overline{\mathrm{X}}}+\left(\mathrm{A}_{2} \overline{\mathrm{R}}\right)$

$=48.1468+(1.023 * 2.4552)=50.66$

L.C.L $=\overline{\bar{X}}-\left(\mathrm{A}_{2} \overline{\mathrm{R}}\right)$

$=48.1468-(1.023 * 2.4552)=45.64$

Control limit for $\mathrm{R}$ Chart

Centre line $\overline{\mathrm{R}}=(\mathrm{R} 1+\mathrm{R} 2+\ldots+\mathrm{Rn}) / \mathrm{n}$

$=2.4552$

U.C.L $=\mathrm{D} 4 * \overline{\mathrm{R}}=2.575 * 2.4552=6.322$

L.C.L $=\mathrm{D} 3 * \overline{\mathrm{R}}=0 * 2.4552=\mathrm{o}$

\section{$\mathrm{x}^{-}$chart}
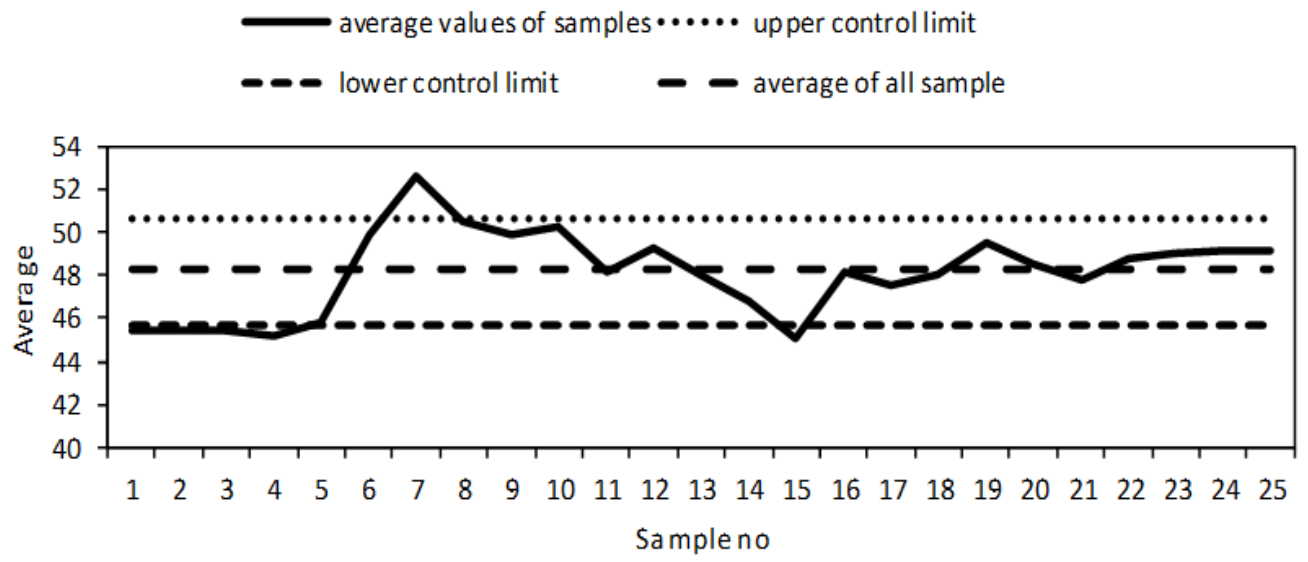


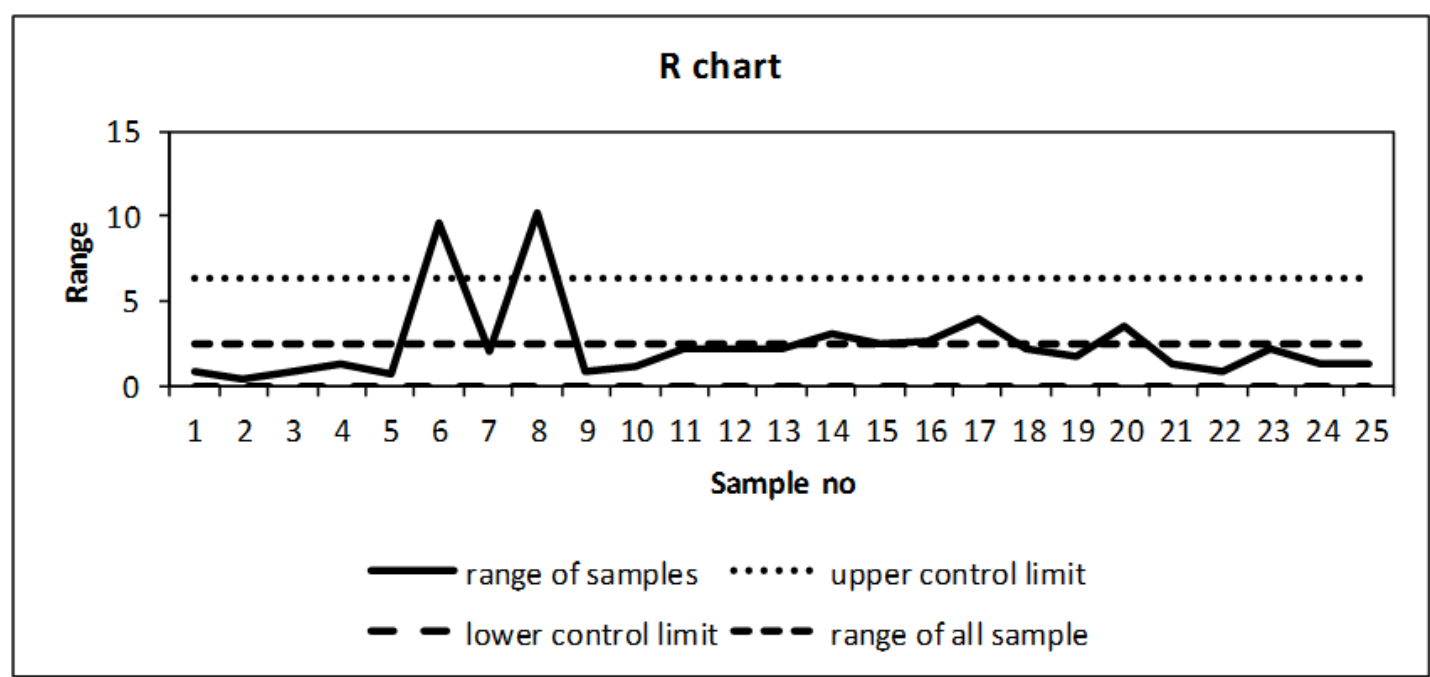

Fig 1. Control chart for cube compressive strength

From the above $\overline{\mathrm{X}}$ control chart it is found that some of the plotted points are outside the trial control limits, i.e. the process is not in control. These control limits cannot be used for further sample as some points are outside control limits. From range chart it is observed that there is variation in the observation of two sample as the range chart is used to detect the variation in observation of sample.

For further calculation, new trial of 25 samples of cube are taken for the recalculation of control limits of $\overline{\mathrm{X}}$ control chart and $\mathrm{X}$ control chart is developed. From this control chart it is observed that no points are outside of control limits so these control limits are extended for further sample. Because at every time, taking sample and calculating control limits for that sample is time consuming job though it improves accuracy of calculating control limits. So if plotted points are not outside the control limits for first trial then these limits can be used for next trial and if not then next trial can be conducted. This is a trial and error type of process. So few samples are taken for drawing control chart. The calculation of control limits for next trial control chart is shown below and also control chart is developed.

Control limit calculation for Control Charts

Control limits for $\overline{\mathrm{X}}$ Chart

Centre line $=\overline{\overline{\mathrm{x}}}=\left(\overline{\mathrm{x}}_{1}+\overline{\mathrm{x}}_{2}+\ldots+\overline{\mathrm{x}}_{\mathrm{n}}\right) / \mathrm{n}$

$$
\overline{\overline{\mathrm{X}}}=48.2816
$$

U.C.L $=\overline{\mathrm{X}}+\left(\mathrm{A}_{2} \overline{\mathrm{R}}\right)$

$=48.2816+(1.023 * 1.4788)$

$$
=46.768
$$

L.C.L $=\overline{\overline{\mathrm{X}}}-\left(\mathrm{A}_{2} \overline{\mathrm{R}}\right)$

$$
\begin{aligned}
& =48.2816-(1.023 * 1.4788) \\
& =46.768
\end{aligned}
$$

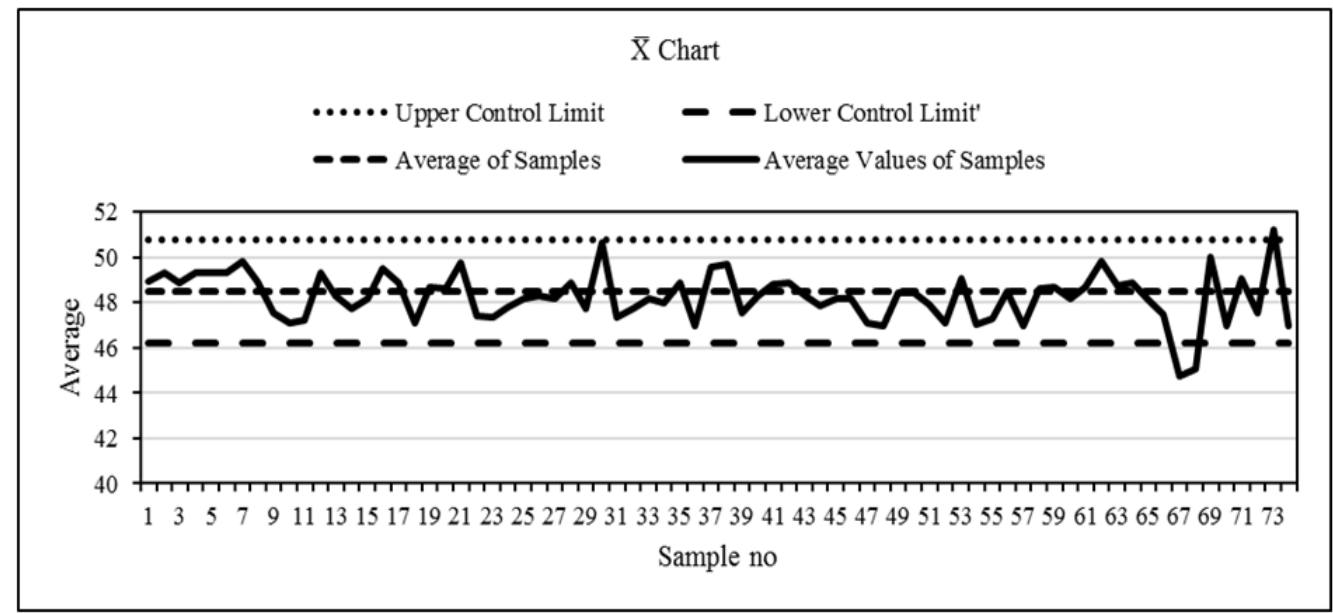

Fig 2. X Control Chart for Cube Compressive Strength. 
From the graph it is found that points are not near to mean value. It means, though the process is statistically in control but there is lack of consistency in process of concreting. It may lead to out of control state and this will cause scrap work or rework.

\section{Evaluation Of Quality Of Concrete Road Project After The Construction}

The Quality of concrete road project after the construction is measured in the terms of core compressive strength. Generally, cores are taken from the concrete road and these cores are tested for compressive strength. Based on this compressive strength of cores, quality of concrete road is decided in the terms of percentage of defects found. It means that measured compressive strength of core is compared with specified range and if these values fall below the specified range then that part of concrete road is declared as defective.

As per the specification of concrete road, three cores should be tested for every 150 cum of accomplished part of the concrete road. Such a lot of 20 sample from accomplished part of concrete road are taken for the evaluation of quality of concrete road. The quality of road depends upon compressive strength of core, which is variable type of characteristic. So the variable acceptance sampling plan is used to evaluate quality of concrete road after the construction. This plan includes quality indices, acceptable quality level, and inspection level. These plans are referred from MIL-STD-414.

For given road project, AQL and inspection level for lot is given as $4 \%$ and normal inspection level. Based on this AQL and lot size, a random four samples are taken from the lot as per the MIL-STD-414. The observation table and calculation for acceptance plan are shown below.

Table 2. Observation table for Core Compressive Strength

\begin{tabular}{|l|l|l|l|l|}
\hline Sr.No & $\begin{array}{l}\text { Core Chainage } \\
\& \text { Location }\end{array}$ & $\begin{array}{l}\text { Height of Core } \\
(\mathrm{mm})\end{array}$ & Diameter of Core $(\mathrm{mm})$ & $\begin{array}{l}\text { Compressive Strength of } \\
\text { Core }(\mathrm{N} / \mathrm{mm} 2)\end{array}$ \\
\hline 1 & 950 & 280 & 143 & 41.16 \\
\hline 2 & 3446 & 280 & 143 & 34.58 \\
\hline 3 & 3418 & 143 & 42.56 \\
\hline 4 & 3740 & 143 & 32.86 \\
\hline Average & 280 & 37.79 \\
\hline Standard deviation & & 4.786049171 \\
\hline
\end{tabular}

As in the Specification of road, lower specification limit for compressive strength of core is specified. Lower specification limit is equal to 0.8 characteristic strength of core, as road is constructed with M40 grade of concrete, so lower specification limit $=0.8 * 40=32 \mathrm{~N} / \mathrm{mm}^{2}$

Quality Index,

$$
\begin{aligned}
\mathrm{Q}_{\mathrm{L}} & =\frac{\overline{\mathrm{X}}-\mathrm{L}}{\mathrm{S}} \\
& =(37.79-32) / 4.78 \\
& =1.21
\end{aligned}
$$

From table of MIL-STD-414, form $n$ and $\mathrm{Q}_{\mathrm{L}}$

Lot Percent Defective below Lower Specification Limit, $\mathrm{P}_{\mathrm{L}}=9.67$

Maximum Allowable Percentage Defective below L based on AQL and Sample no, $\mathrm{M}_{\mathrm{L}}=10.92$.

$\mathrm{P}_{\mathrm{L}}<\mathrm{M}_{\mathrm{L}}$

So the lot meets the acceptance criteria. The work satisfies the quality requirement as per the specification of road Further an individual control chart i.e. moving range is developed for the lot in order to show the variation of density of core.

The control limit calculation for moving range chart in order to show variation of density are shown below.

Control limits for Moving Range Chart

Upper Control Limit (U.C.L) $=\overline{\mathrm{X}}+\mathrm{E}_{2} \overline{\mathrm{R}}$

As here only range of two samples are taken so from table $E_{2}=2.66$

U.C.L $=(2331.329+2.66 * 87.54)$

$$
=2564.19 \mathrm{~kg} / \mathrm{cum}
$$

Centre Line $=$ Average Value ie. $\overline{\mathrm{X}}$

$$
=2331.3295 \mathrm{~kg} / \mathrm{cum}
$$

Lower Control Limit $=\overline{\mathrm{X}}-\mathrm{E}_{2} \overline{\mathrm{R}}$

As $\mathrm{E}_{2}=2.66$

$$
\begin{aligned}
\text { L.C.L } & =(2331.329-2.66 * 87.54) \\
& =2098.46 \mathrm{~kg} / \mathrm{cum}
\end{aligned}
$$




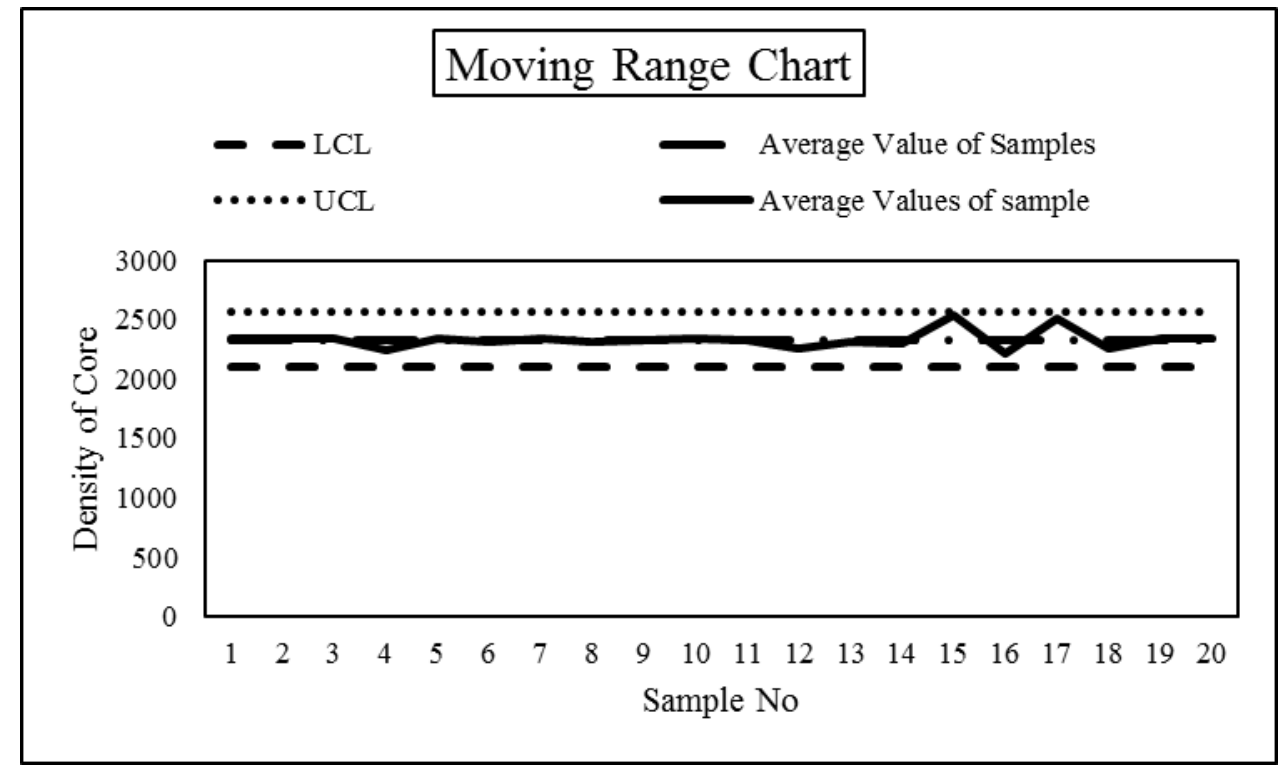

Fig 3. Moving Range Chart for Core Density

The graph shows the variation of density of concrete for respective chainages.

\section{Conclusion}

From the analysis, it is found that quality of concrete road project meets the specified criteria. From control chart, it is found that there is lack of consistency in process of concreting but lots of plotted points on the chart are within the control limits which proves that there are no assignable type of variation in concreting process. From acceptance sampling plan, quality of concrete road project meets the specification requirement.

The statistical quality control tools are very important for identifying causes behind the quality deployment of the process of manufacturing products. From statistical process control tools such as control charts, it is easy to monitor quality of product during the manufacturing process and this will avoid the future rework and cost related to it. From acceptance sampling plan, it is easy to accept or reject the lot based on their acceptance criteria. These acceptance plans give idea about how much quantity of sample should be taken from the lot for inspection and acceptance of lot based on this inspection. These plans avoid 100\% inspection which is more time consuming procedure.

\section{References}

[1]. Bubshait A. A and Tawfiq H. A. (1999). "ISO 9000 Quality Standards in Construction", American Society of Civil Engineers J. Manage. Eng., 1999.15:41-46

[2]. Changl L.M. and Hsie M. (1995) "Developing Acceptance-Sampling Methods for Quality Construction”, American Society of Civil Engineers, J. Eng. Manage. 1995.121:246-253

[3]. Gharaibeh N. G and Wani S. S, (2012). "Skip-Lot Acceptance Sampling Plans for Highway Construction and Materials". American Society of Civil Engineers J. Constr. Eng. Manage.138:791-796. DOI: 10.1061/ (ASCE) CO.1943-7862.0000494.

[4]. Kosnik D. E, Zhang W and Pablo L. D, (2013). "Application of Statistical Process Control for Structural Health Monitoring of a Historic Building”, American Society of Civil Engineers, J. Infrastructure. Syst. DOI: 10.1061/(ASCE)IS.1943-555X.0000164.

[5]. MIL-STD-414. (1957). Sampling Procedure and Tables for Inspection by Variables for Percentage Defective

[6]. Nassar K. M, Walid M. N. and Mohamed Y. Hegab3 (2005). "Evaluating Cost Overruns of Asphalt Paving Project Using Statistical Process Control Methods", American Society of Civil Engineers. DOI: 10.1061/(ASCE)0733-9364(2005)131:11(1173).

[7]. Snow. C. H. (1985) "Statistical Analysis of Specification Compliance" American Society of Civil Engineers J. Transp. Eng...111:280-29 pp.280-291.

[8]. Unanwa C. and Mahan M (2014). "Statistical Analysis of Concrete Compressive Strengths for California Highway Bridges", American Society of Civil Engineers J. Perform. Constr. Facil...28:157-167. DOI: 10.1061/ (ASCE) CF.1943-5509.0000404.

[9]. Wang Y, Xuan1 W.H and Xiang M.A (2010). "Statistical Methods Applied to Pavement Construction Quality Assurance", American Society of Civil Engineers, ICCTP. 